\title{
Efficient and long-term stable organic vacuum deposited tandem solar cells
}

\author{
Christian L. Uhrich*a, Gregor Schwartz ${ }^{\mathrm{a}}$, Bert Maennig ${ }^{\mathrm{a}}$, Wolf M. Gnehr ${ }^{\mathrm{a}}$, Stefan Sonntag ${ }^{\mathrm{a}}$, Oliver \\ Erfurth $^{\mathrm{a}}$, Eginhard Wollrab ${ }^{\mathrm{a}}$, Karsten Walzer ${ }^{\mathrm{a}}$, Jan Foerster ${ }^{\mathrm{a}}$, Andre Weiss ${ }^{\mathrm{a}}$, Olga Tsaryova ${ }^{\mathrm{a}}$, Karl \\ Leo $^{\mathrm{b}}$, Moritz K. Riede ${ }^{\mathrm{b}}$, Martin Pfeiffer ${ }^{\mathrm{a}}$ \\ ${ }^{a}$ Heliatek GmbH, Liebigstr. 26, 01187 Dresden, Germany; \\ ${ }^{\mathrm{b}}$ Technische Universität Dresden, Institut für Angewandte Photophysik, 01062 Dresden
}

\begin{abstract}
We report on the latest progress in the field of organic p-i-n tandem solar cells. The external quantum efficiencies of a tandem solar cell with two complementary absorbing bulk heterojunctions with an efficiency of $6.07 \%$ (certified by Fraunhofer ISE) with an active area of about $2 \mathrm{~cm}^{2}$ is analyzed. These solar cells are extremely stable: a reduction of only $3 \%$ of its initial power conversion efficiency was measured when stored at $85^{\circ} \mathrm{C}$ for 5000 hours. The solar cell does not show any reduction in efficiency when stored under continuous illumination of a tungsten lamp corresponding to 1.5 suns for 5000 hours. Furthermore, we present the latest results on optimized tandem solar cells showing a power conversion efficiency of $7.66 \%$ (certified by Fraunhofer ISE, active area of $1.1 \mathrm{~cm}^{2}$ ).
\end{abstract}

Keywords: organic tandem solar cell, vacuum deposition, power conversion efficiency, lifetime

\section{INTRODUCTION}

Organic solar cells can be produced on large area, the modules can be light weight, flexible, and optically translucent, and they can be produced with low material and energy consumption at low costs. In 1986, Tang reported about the first organic heterojunction cell with an efficiency of about $1 \%{ }^{1}$. Since then a lot of progress regarding efficiency, lifetime and the understanding of the physics behind organic solar cells has been achieved ${ }^{2,3,4,5,6,7}$. Recently, an organic bulk heterojunction polymer solar cell with record efficiency as high as 7.9\% has been reported (NREL 'Notable exception' of a polymer solar cell with an active area of $4.4 \mathrm{~mm}^{2}$ produced by Solarmer) ${ }^{8}$. This progress and the availability of first products ${ }^{9}$ show that organic heterojunction solar cells are close to commercialization.

In this article, we will present the progress in p-i-n tandem solar cells processed from small molecules by vacuum deposition. With this technique, it is possible to prepare organic solar cells with high power conversion efficiencies and simultaneously extremely long lifetime.

*christian.uhrich@heliatek.com; www.heliatek.com

Organic Photonics IV, edited by Paul L. Heremans, Reinder Coehoorn, Chihaya Adachi, Proc. of SPIE Vol. 7722, 77220G · (C) 2010 SPIE · CCC code: 0277-786X/10/\$18 · doi: 10.1117/12.855088 


\section{EXPERIMENTAL}

Organic tandem solar cells based on the p-i-n-concept ${ }^{5}$ were prepared and investigated. The solar cells consist of two bulk-heterojunctions (BHJ), each with complementary absorbing donor materials and C60 as acceptor material, embedded between doped organic transport layers. The organic dopants are provided by Novaled AG, Dresden; the donor material for absorption in the red spectral region is provided by BASF, Ludwigshafen. The absorber for the green spectral region is a conjugated oligomer developed and synthesized by Heliatek GmbH. Using highly conductive doped wide gap hole transport layers adjacent to the reflecting metal top contact and between the two BHJs allows for an optimal positioning of each subcell regarding optical interference maxima ${ }^{10,11}$. All devices are prepared on indium tin oxide-coated glass substrates (Thin Film Devices Inc., Anaheim, USA) with a sheet resistance of $30 \Omega / \square$ precleaned with organic solvents in an ultrasonic bath. The organic layers and the metal top contact were deposited through shadow masks.

The device which will be discussed firstly has a photoactive area of $2 \mathrm{~cm}^{2}$ while the second device shows an active area of $1.1 \mathrm{~cm}^{2}$.

The devices were encapsulated together with a getter pad with a glass lid glued by a UV-curable epoxy resin in a nitrogen atmosphere.

The measurements of the external quantum efficiency (EQE) were carried out with a custom-made setup. The monochromatic probe beam is chopped and the solar cell's current response is detected via lock-in amplifier. Bias illumination is provided by LEDs.

Both of the solar cells shown in this paper were certified by Fraunhofer-ISE (Freiburg, Germany).

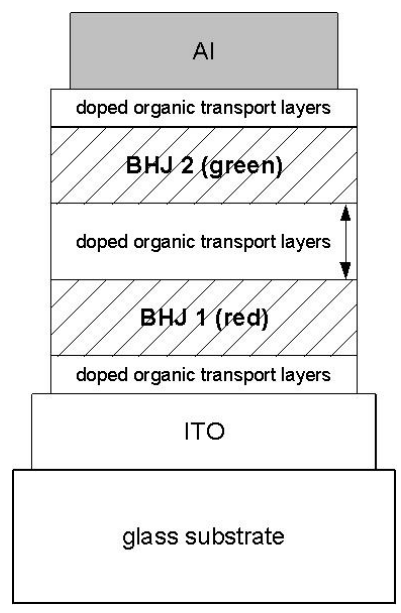

Figure 1 Tandem solar cell

The lifetime of two solar cells with a similar layer structure as Cell $\mathbf{A}$ was measured. Cell $\mathbf{A - 1}$ has been stored in the dark at $85^{\circ} \mathrm{C},<30 \%$ r.h. This is not only an accelerated shelf life test for the stability of the encapsulation, but also certainly tests the intrinsic long-term thermal stability of the cell itself. 


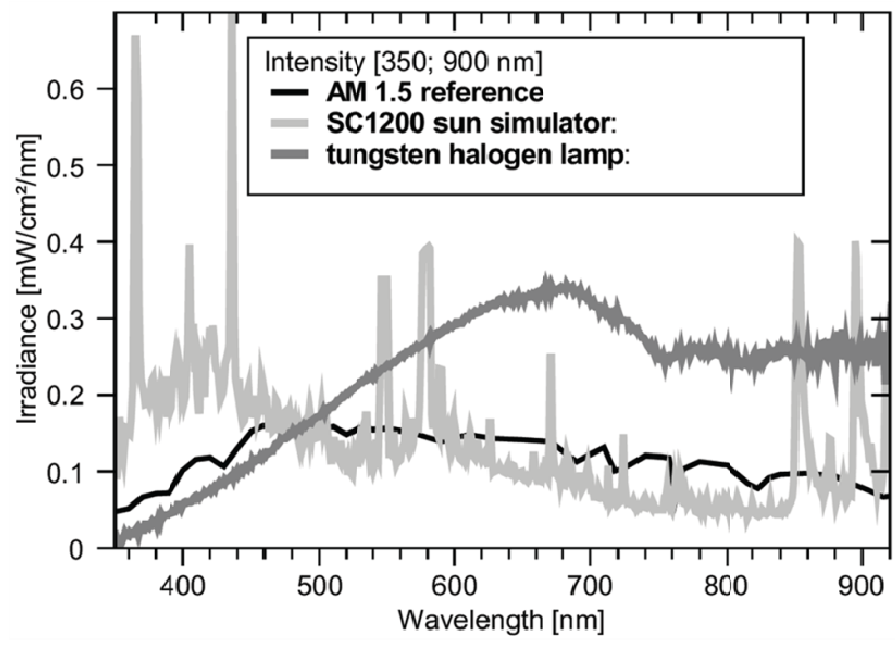

Figure 2 Spectra of the tungsten halogen lamp used for the stress tests under continuous illumination, and the SC1200 sun simulator used for current-voltage measurement, together with the AM1.5 reference spectrum.

Solar Cell A-2 has been stored under continuous illumination with a tungsten halogen lamp under open circuit conditions. Cell temperature was around $50^{\circ} \mathrm{C},<30 \%$ r.h. The spectrum of the lamp at the position of the samples is shown in Figure 1 and compared to the standard AM1.5 reference spectrum. Significant intensity from the lamp starts in the near UV at $350 \mathrm{~nm}$. The spectrum is measured with a calibrated Ocean Optics USB4000 spectrometer. The short circuit current density (Jsc) of cell A-2 measured under these stress conditions corresponds to 1.5 times the value of Jsc measured under AM1.5g; $1000 \mathrm{Wcm}^{-2}$.

Periodic measurements have been carried out under the calibrated SC1200. Before each measurement, samples have been allowed to cool down to room temperature.

\section{RESULTS AND DISCUSSION}

Organic molecules typically used in small molecule organic solar cells can have extremely high extinction coefficients but often show a relatively narrow bandwidth. Tandem solar cells with complementary absorbing subcells overcome this problem. In Figure 3, the absorption spectra of the two donor-type materials used in the two sub cells of solar cell $\mathbf{A}$ are shown. The combination of these two materials with $\mathrm{C} 60$ allows the coverage of the whole visible sun spectrum from 300 to $800 \mathrm{~nm}$. 


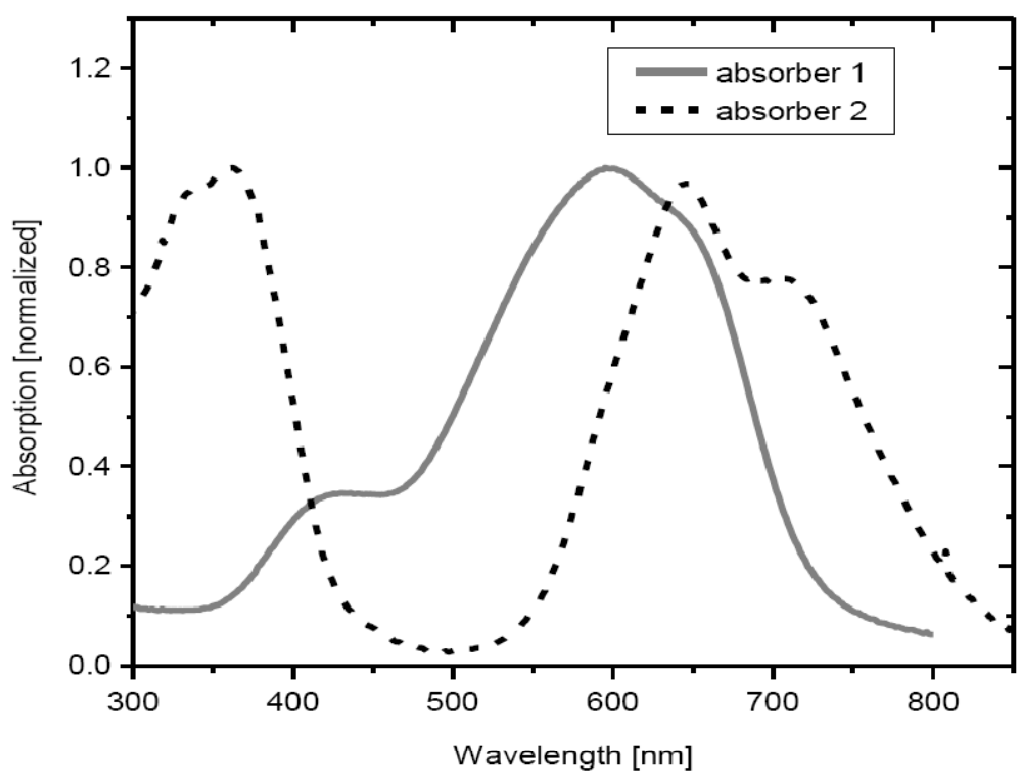

Figure 3 Absorption spectra of the two donor materials used in cell $\mathbf{A}$.

Another advantage of tandem solar cells is the possibility to optimize the open circuit voltage (Voc). The Voc of each sub cell can be optimized individually. Voc of a solar cell is ultimately limited by the low energy absorption edge of the photoactive materials in each sub cell. Thus, using tandem solar cells, more energy per photon can be extracted from the solar cell. Ideally, Voc of a tandem solar cell is the sum of the Vocs of each sub cell. Here, the interconnection of the two sub cells is realized using highly doped transport layers ${ }^{11}$.

Furthermore, the concept of small molecule organic tandem solar cells in combination with doped wide gap transport layers permits placing each sub cell in the optimum distance to the reflecting aluminum top contact regarding optical interference effects. Thus, it is possible to design a tandem solar cell covering the whole visible sun spectrum, to optimize Voc and achieve current matching between the two sub cells. 


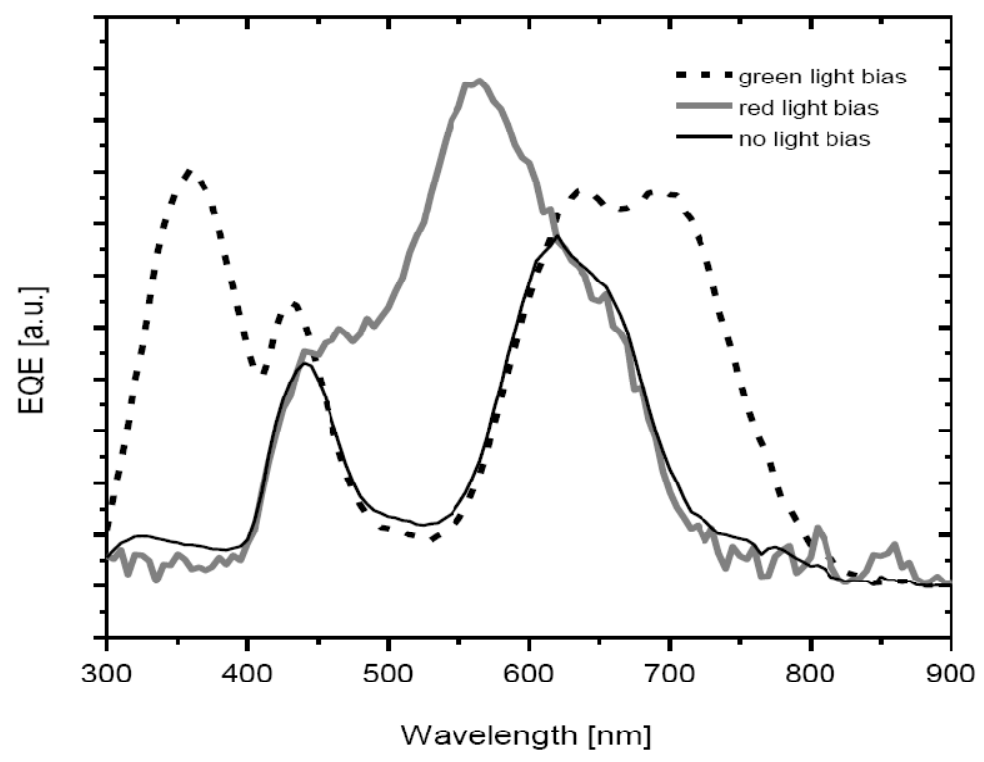

Figure 4 EQE of tandem solar cell $\mathbf{A}$ measured with various light bias.

Figure 4 shows the external quantum efficiency (EQE) of tandem solar cell $\mathbf{A}$ measured under various light biases. The Graph shows EQE measurements with green $(500 \mathrm{~nm})$, red $(650 \mathrm{~nm})$ and no light bias. The EQE measurements with light bias in combination with lock-in technique allows for the determination of the individual EQEs of each sub cell of this tandem solar cell with complementary absorbing bulk heterojunctions. Using the green light bias, the green absorbing sub cell is mainly excited such that the second sub cell is limiting the overall current of the tandem cell (dashed line). The spectrum shows two maxima, one around $350 \mathrm{~nm}$ and another at $680 \mathrm{~nm}$ reflecting the absorption spectrum of donor material 2 shown in Figure 3. Using a red light bias, the second sub cell (absorbing mainly in the green wavelength region) limits the overall current of the tandem solar cell and its EQE becomes visible (grey thick line). This spectrum features only one maximum around 550nm. If no light bias is used (thin black line), the overall current is limited by the lower current of the two sub cells. In theory, the EQE measured without light bias should be the lower envelope of the EQEs of the respective sub cells. The agreement between measurement and theory confirms a good rectifying behavior of each sub cell.

The short circuit current density (Jsc) of a solar cell can be calculated from its EQE and the illumination spectrum. Using the EQEs of cell A and the AM1.5g spectrum (ASTM G173, Figure 2) one obtains $6.13 \mathrm{mAcm}^{-2}$ for the sub cell absorbing mainly in the red (green light bias) and $6.19 \mathrm{mAcm}^{-2}$ for the sub cell absorbing mainly in the green wavelength region (red light bias). The measurements show a very good current matching of the two sub cells when illuminated with the AM $1.5 \mathrm{~g}$ spectrum. 


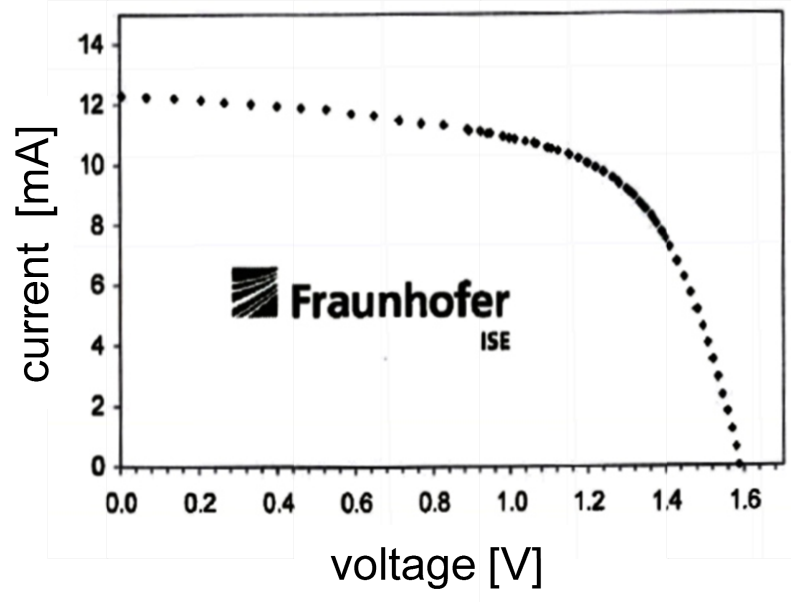

Figure 5 IV-characteristics of tandem solar cell A certified by Fraunhofer ISE under STC (area $1.989 \mathrm{~cm}^{2}$ ).

The tandem solar cell was then measured under STC $\left(1000 \mathrm{Wm}^{-2}, 25^{\circ} \mathrm{C}, \mathrm{AM} 1.5 \mathrm{~g}\right)$ by Fraunhofer $\mathrm{ISE}^{8}$ :

$\begin{array}{ll}\text { Voc } & =1.59 \mathrm{~V} \\ \text { Jsc } & =6.18 \mathrm{mAcm}^{-2} \\ \text { FF } & =61.9 \% \\ \eta & =6.07 \%\end{array}$

The aperture is $1.989 \mathrm{~cm}^{2}$. The IV-characteristics are shown in Figure 5. The measured Jsc is in good agreement with the smaller current calculated from the EQE measurements.

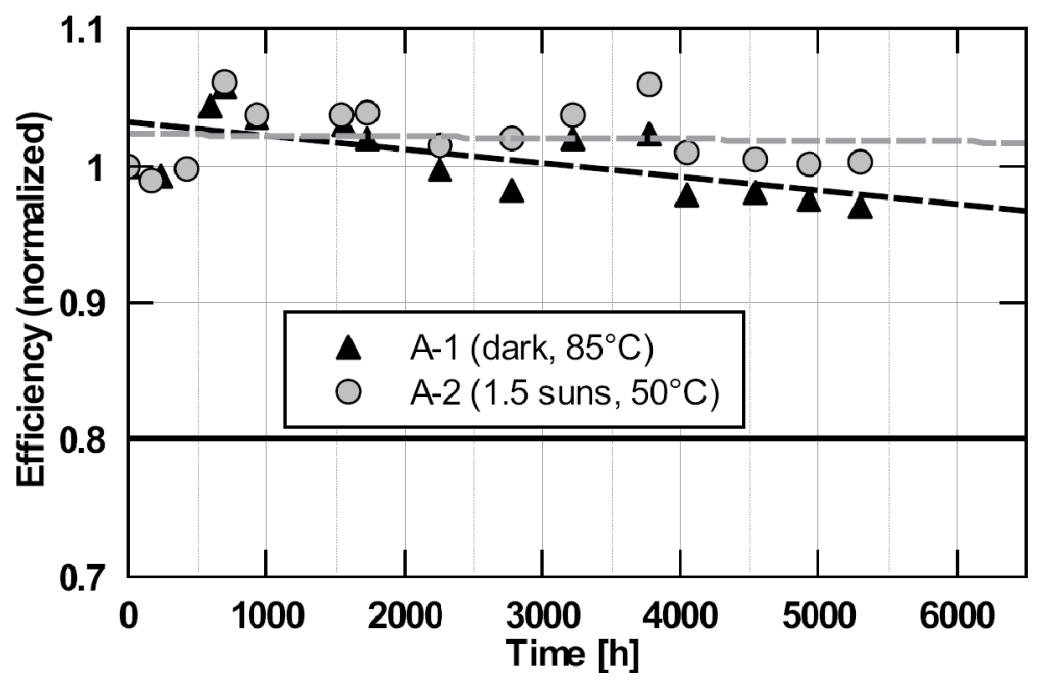

Figure 6 Normalized power conversion efficiency vs. time of two tandem solar cells A-1 and A-2. A-1 was stored at $85^{\circ} \mathrm{C},<30 \%$ r.h. in the dark; $\mathbf{A}-2$ was stored under continuous illumination (tungsten halogen lamp; $50^{\circ} \mathrm{C}$ ) and periodically measured over more than 5000 hours. Scattering of data points is attributed to small differences from measurement to measurement in temperature, lamp spectrum and contact resistivity. 
Two solar cells (A-1 and A-2) were prepared similar to tandem solar cell $\mathbf{A}$. These cells have an active area of about $6 \mathrm{~mm}^{2}$. Both cells showed efficiencies comparable to $\mathbf{A}$. With both cells, lifetime measurements were performed for about 5300 hours (Figure 6). Tandem solar cell A-1 was stored in the dark at $85^{\circ} \mathrm{C},<30 \%$ r.h.. Solar cell A-2 was stored under continuous illumination under Voc conditions (cf. spectrum in Figure 2). Figure 6 shows the relative development of the solar cells efficiencies measured periodically under sun simulator SC1200 (see spectrum in Figure 2). Scattering of data points is attributed to small drifts in temperature, lamp spectrum and contact resistivity between measurements. Tandem Cell A-1 (dark, $85^{\circ} \mathrm{C}$ ) shows a reduction in efficiency of about $3 \%$ from its initial value after 5300 hours. Solar Cell A-2 $\left(1.5\right.$ suns, $\left.50^{\circ} \mathrm{C}\right)$ shows no degradation at all after 5300 hours.

The data points of each measurement sequence were fitted linearly (dashed black and grey line). Due to the scattering of data points, the extrapolated lifetimes ( $80 \%$ of the cells initial power conversion efficiency) cannot yet be reasonably determined.

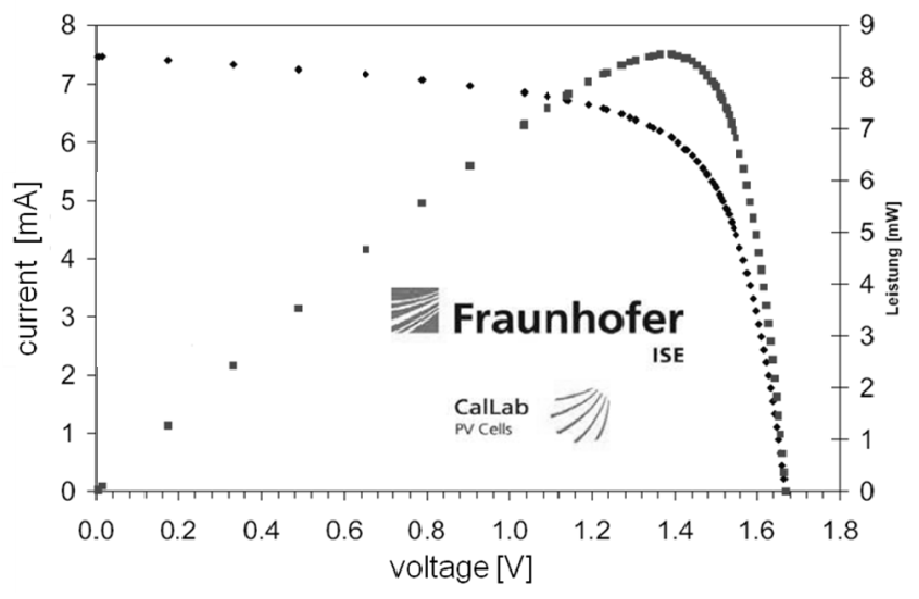

Figure 7 IV-characteristics of optimized tandem solar cell B certified by Fraunhofer ISE under STC (area $\left.1.103 \mathrm{~cm}^{2}\right)$.

The latest results on organic tandem solar cells are shown in Figure 7. An optimized tandem solar cell $\mathbf{B}$ has been prepared. The aperture area of this cell is $1.103 \mathrm{~cm}^{2}$. Cell $\mathbf{B}$ was measured by Fraunhofer ISE as well. The measurements under STC $\left(1000 \mathrm{Wcm}^{-2}, 25^{\circ} \mathrm{C}\right.$, AM1.5g) yielded the following results:

$\begin{array}{ll}\text { Voc } & =1.67 \mathrm{~V} \\ \text { Jsc } & =6.78 \mathrm{mAcm}^{-2} \\ \mathrm{FF} & =67.7 \% \\ \eta & =7.66 \%\end{array}$

This is the highest efficiency value for organic solar cells reported on an area larger than $1 \mathrm{~cm}^{2}$. The certified IVcharacteristics are shown in Figure 7.

\section{SUMMRY AND OUTLOOK}

We have shown small molecule p-i-n tandem solar cells with efficiencies of $6 \%$, a very good current matching of the sub cells and an intrinsically high stability. The cells show a relative reduction of the initial efficiency of about $3 \%$ when stored for 5000 hours at $85^{\circ} \mathrm{C}$ and no reduction in efficiency when stored under continous illumination of a tungsten lamp corresponding to 1.5 suns for 5300 hours as well. The latest results on tandem solar cells are optimized cells with efficiencies of up to $7.66 \%$ (certified by Fraunhofer ISE).

The next step towards ("toward" für AE laut leo) a commercialization of small molecule organic solar cells is to establish a cost efficient production process competitive to existing thin-film solar cell technologies. Consequently, the efficiencies of organic solar cells have to be further increased. An obvious possibility is to increase Jsc by harvesting photons also in the near infrared wavelength region. To fully profit from the advantages of organic solar cells, the results 
of efficiency and lifetime have to be transferred to flexible substrates. Here, the major issues are the development of a cost efficient barrier system and to find an alternative to ITO.

\section{ACKNOWLEDGEMENTS}

This work is funded by the Bundesministerium für Bildung und Forschung (BMBF) via the OPEG project (13N9716), and by the Sächsische Aufbaubank (SAB) (12716/2112). We thank Peter Erk and Jaehyung Hwang from BASF and Peter Baeuerle from the Institut für Organische Chemie II, Universität Ulm for good cooperation.

\section{REFERENCES}

${ }^{1}$ C. W. Tang, Appl. Phys. Lett. 48, 183 (1986).

${ }^{2}$ P. Peumans, and S. R. Forrest, Appl. Phys. Lett. 79, 126 (2001).

${ }^{3}$ P. Peumans, S. Uchida, and S. R. Forrest, Nature 158, 425 (2003).

${ }^{4}$ J. Xue, S. Uchida, B. P. Rand, and S. R. Forrest, Appl. Phys. Lett 85, 5757 (2004).

${ }^{5}$ B. Maennig, J. Drechsel, D. Gebeyehu, P. Simon, F. Kozlowski, A. Werner, F. Li, S. Grundmann, S. Sonntag, M.

Koch, K. Leo, M. Pfeiffer, H. Hoppe, D. Meissner, N.S. Sariciftci, I. Riedel, V. Dyakonov, and J. Parisi, Appl. Phys. A 79, 1 (2004).

${ }^{6}$ R. Schueppel, K. Schmidt, C. Uhrich, K. Schulze, D. Wynands, J. Brédas, E. Brier, E. Reinold, H. Bu, P. Baeuerle, B. Maennig, M. Pfeiffer, K. Leo, phys. rev. B 77, 085311 (2008).

${ }^{7}$ C. Uhrich, D. Wynands, S. Olthof, M. Riede, K. Leo, S. Sonntag, B. Maennig, M. Pfeiffer, J. Appl. Phys. 104, 043107 (2008).

${ }^{8}$ M. A. Green, K. Emery, Y. Hishikawa and W. Warta, Prog. Photovolt: Res. Appl. 18, 144 (2010)

${ }^{9} \mathrm{http}: / /$ www.konarka.com

${ }^{10}$ J. Drechsel, B. Maennig, F. Kozlowski, M. Pfeiffer, K. Loe, H. Hoppe, Appl. Phys. Lett. 86, 244102 (2005).

${ }^{11}$ R. Schueppel, R. Timmreck, N. Allinger, T. Mueller, M. Furno, C. Uhrich, K. Leo, M. Riede, J. Appl. Phys. 107, 044503 (2010) 